\title{
Green synthesis, characterization and optical properties of eutectics and 1:1 intermolecular compounds: $N, N$-dimethylaminobenzaldehyde-anthranilic acid and 2-(4-(dimethylamino)benzylideneamino)benzoic acid- $p$-nitroaniline systems
}

\author{
U S RAI*, MANJEET SINGH and R N RAI \\ Department of Chemistry, Institute of Science, Centre of Advanced Study, Banaras Hindu University, Varanasi 221005, \\ India \\ *Author for correspondence (usrai_bhu@ yahoo.co.in)
}

MS received 19 September 2017; accepted 17 June 2018; published online 6 March 2019

\begin{abstract}
Phase diagrams of $N, N$-dimethylaminobenzaldehyde (DMAB)-anthranilic acid (AA) and 2-(4(dimethylamino)benzylideneamino)benzoic acid (DMABAB)-p-nitroaniline (PNA) systems, determined by the thaw-melt method, give two eutectics and a 1:1 intermolecular compound (IMC) in each case. Appropriate amounts (10 g) of each of the eutectics and the IMCs were prepared by a green synthetic method involving a solid state reaction without any solvent. These materials were characterized by X-ray diffraction, thermal and spectral methods and the optical properties of the pure components and the IMCs were studied. While negative values of heat of mixing in the case of a DMAB-AA system suggest clustering of molecules in both eutectic melts, those of positive value in $E_{1}$ and negative value in $E_{2}$ of the DMABAB-PNA system indicate the formation of a quasi-eutectic structure in $\mathrm{E}_{1}$ melt and clustering of molecules in $\mathrm{E}_{2}$ melt. The IMC of DMAB-AA system shows strong dual emission with two $\lambda_{\max }$ one at $380 \mathrm{~nm}$ and the second at $450 \mathrm{~nm}$ with a total quantum efficiency of 0.49. The IMC of DMABAB-PNA system also shows a similar observation with two $\lambda_{\max }$ one at $390 \mathrm{~nm}$ and second at $435 \mathrm{~nm}$ with a total quantum efficiency of 0.31 .
\end{abstract}

Keywords. Phase-diagram; inter-molecular compound; heat of fusion; powder XRD; optical properties.

\section{Introduction}

It is well known that the increasing demand for materials to cater to the needs of modern civilization is a global challenge for chemists, physicists, metallurgists and materials scientists. It is of immense importance to develop more and more materials with specific properties at low cost. Metallic poly-phase alloys, namely, metal eutectics, monotectics and inter-metallic compounds offer an interesting area of investigation [1-3] in metallurgy and materials science to develop new materials of commercial and technical importance. But due to high transition temperature, difficulties involved in their purification, opacity, large density difference and limited choice of materials, the metallic systems are not suitable for detailed investigations. Organic materials which offer additional advantages in terms of cost, ease of processing and great degree of freedom in properties due to attachment of different functional groups at different position in the compounds are used for different electronic applications including conductors, semiconductors, dielectric, non-linear optics and lasers [4-6]. Horiuchi et al $[7,8]$ have discovered a novel class of binary organic intermolecular compounds (IMCs) in which bonds form a supra-molecular structure where arrangement of molecules in three dimension and crystal structure decides the properties of materials. The IMCs formed by the non-covalent bonding such as hydrogen bonding, polar-polar, polar-induced polar interactions and dispersion forces between the parent components require further exploration to synthesize novel materials [9]. The parent components with acidic or phenol groups are found to be potential candidates for the $\mathrm{O}-\mathrm{H} \cdots \mathrm{O}, \mathrm{O}-\mathrm{H} \cdots \mathrm{N}$ or $\mathrm{N}-\mathrm{H} \cdots \mathrm{O}$ interactions through hydrogen bonds in solid phases [10]. During the last two decades, the potential use of organic compounds for nonlinear optical (NLO) materials and for other electronic applications has prompted the researchers to undertake various physicochemical investigations in detail [11-13]. In addition, they have ability to produce as well as modify, the NLO and white light emitting diode materials $[14,15]$.

With a view to develop novel materials and also throw light on physicochemical interactions among the components, $N, N$-dimethylaminobenzaldehyde (DMAB)-anthranilic acid (AA) and 2-(4-(dimethylamino)benzylideneamino)benzoic 
acid (DMABAB) - $p$-nitroaniline (PNA) systems were chosen and their phase diagrams, X-ray diffraction (XRD) and spectral and thermal behaviour were studied. The optical emissions and fluorescence properties were also studied in a suitable solvent.

\section{Experimental}

\subsection{Materials and their purification}

All compounds, namely, AA (99\%), DMAB (99\%) and PNA (99\%) obtained from Aldrich (Germany), were further purified by repeated crystallization from ethyl acetate. The purity of each of the materials was ascertained by comparing their melting temperatures provided in the literature [16]. The experimental melting temperatures of AA, DMAB and PNA were found to be 148,74 and $149^{\circ} \mathrm{C}$, respectively. DMABAB was synthesized by green synthesis by taking a 1:1 molar ratio of $\mathrm{AA}$ and $\mathrm{DMAB}$ in a test tube, homogenized them properly by heating at $185^{\circ} \mathrm{C}$ in a silicone oil bath and after the reaction was complete the solution was cooled in an ice bath and then purified by repeated crystallization from methanol.

\subsection{Phase diagram}

The phase diagrams of DMAB-AA and DMABAB-PNA systems were determined by the thaw-melt method [17] in the form of a temperature-composition curve. In this method, mixtures of two components, covering the entire range of compositions, were prepared and they were homogenized by repeating the process of their melting followed by chilling in ice cold water five times. The melting temperature of each of compositions was recorded using a melting point apparatus (Toshniwal) attached with a precision thermometer with an accuracy of $\pm 0.5^{\circ} \mathrm{C}$.

\subsection{Spectroscopic studies}

Infrared spectra of the pure components and the IMCs were recorded at $300 \mathrm{~K}$ in the region $4000-400 \mathrm{~cm}^{-1}$ using a PerkinElmer FT-IR Spectrum 1000 infrared spectrometer. The NMR spectra were recorded in $\mathrm{CDCl}_{3}$ using a JOEL $300 \mathrm{MHz}$ spectrometer.

\subsection{Enthalpy of fusion}

The values of heat of fusion of the pure components, the eutectics and the IMCs were determined [18] by the differential scanning calorimetry (DSC) method using (Mettler DSC-4000 System). Indium and zinc samples were used to calibrate the DSC unit. The amount of test sample and heating rate were about $7 \mathrm{mg}$ and $5^{\circ} \mathrm{C} \mathrm{min}^{-1}$, respectively.

\section{$2.5 X$-ray diffraction}

Powder XRD patterns of the pure components, the eutectics and the IMCs were recorded using an $18 \mathrm{~kW}$ rotating $(\mathrm{Cu})$ anode-based Rigaku powder Diffractometer fit with a graphite monochromator in the diffracted beam. The samples were scanned from 10 to $70^{\circ}$ with a scanning rate of $4^{\circ} \mathrm{min}^{-1}$.

\subsection{Optical characterization}

The absorption spectra of all starting compounds and the IMCs were studied using a UV/Vis/NIR (JASCO model V670) spectrometer from 190 to $700 \mathrm{~nm}$ at room temperature in methanol solution $\left(1.0 \times 10^{-5} \mathrm{M}\right)$. Fluorescence spectra were recorded on a Varian Cary Eclipse Fluorescence spectrophotometer using pyrene as a reference at room temperature in the same solvent and concentration.

\section{Results and discussion}

\subsection{Phase diagram}

3.1a DMAB-AA system: The phase diagram of the DMABAA system shows the formation of a 1:1 IMC (DMABAB) with congruent melting point and two eutectics $E_{1}$ and $E_{2}$ containing 0.10 and 0.95 , mole fractions of AA, respectively. The IMC shows a higher melting point compared to both parent materials because there is new covalent bond formation between both parents. The melting points of $E_{1}, E_{2}$ and the IMC are 68,143 and $187^{\circ} \mathrm{C}$, respectively (figure 1). It is obvious from figure 1 that the melting point of DMAB decreases with the addition of the second component AA and it attains the minimum value at the first eutectic point $E_{1}$ because up to this eutectic composition AA behaves just like impurity in DMAB and is completely miscible in DMAB. The eutectic composition also behaves just like a single moiety in which both parents are held together via weak interactions stable in the solid state and dissociate in the liquid state. However, in some cases it also remains stable in the liquid state, especially in deep eutectic solvents [19,20]. Further addition of second component causes the melting point to rise till it attains the maximum at $\mathrm{C}$ where the compositions of liquid and solid phases are identical. This maximum temperature is the congruent melting point of the DMABAB. Further increase in mole fraction of the second component causes the melting point of the mixture to decrease and it attains the minimum at the second eutectic point $\mathrm{E}_{2}$. In the phase diagram, DMABAB behaves just like a parent component for both individual starting parent molecules. The existence of the maximum along with eutectic points on either side of the maximum point imparts stability [21] to the DMABAB. The reaction between the two components can be represented by equation:

$$
\mathrm{A}+\mathrm{B} \rightleftharpoons \mathrm{AB} \text { (solid) } \rightarrow \mathrm{AB} \text { (liquid) }
$$




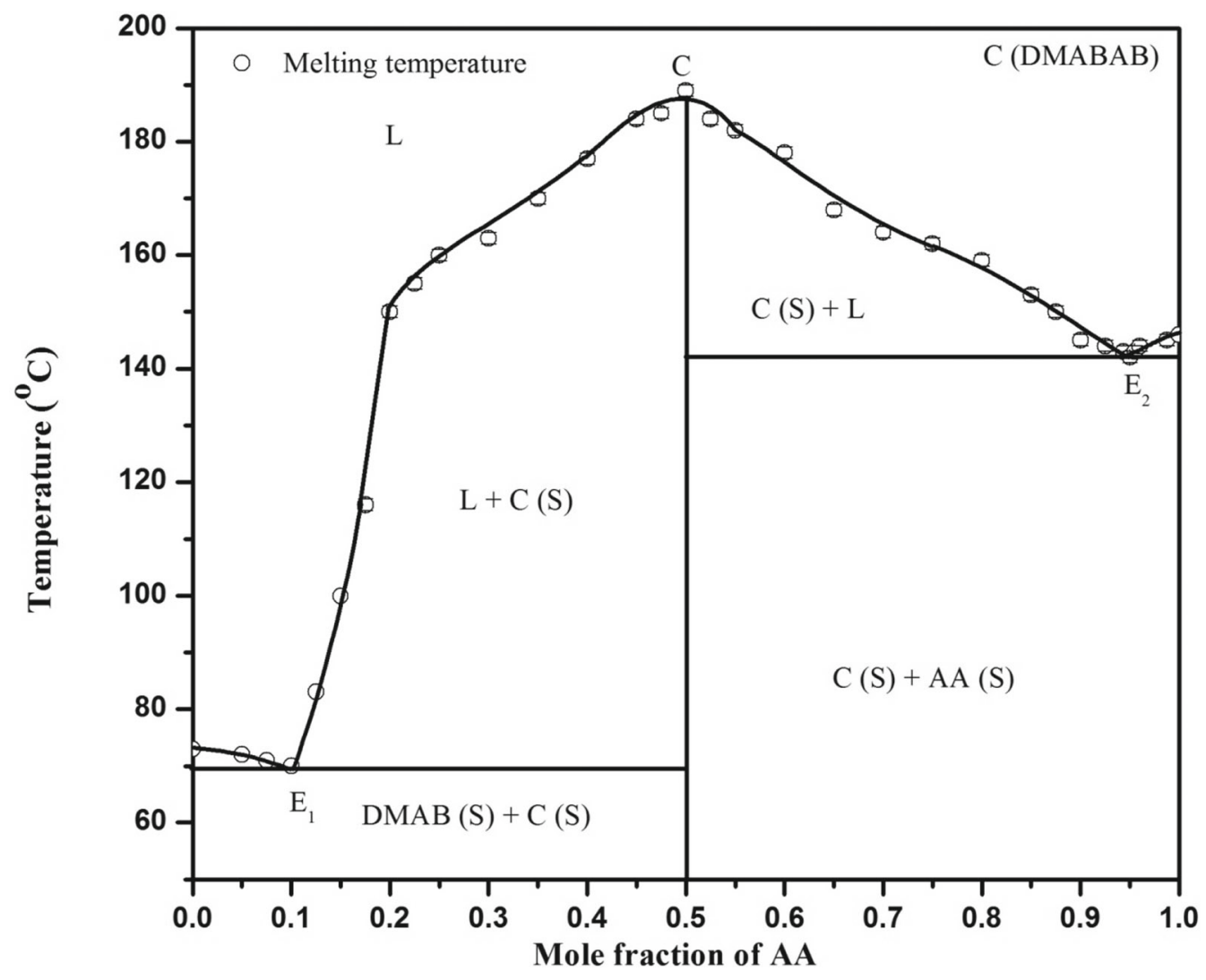

Figure 1. Phase diagram of AA and DMAB system.

In the liquid phase, the addition compound $\mathrm{AB}$ must remain as a single moiety and phase diagram would show a sharp maximum. However, when dissociation occurs in the molten state, the products of dissociation lower the effective mole fraction of the solute, and the curve would be flattened. For each eutectic, DMABAB behaves as one of the components. The observed maximum in the system under investigation is sharp indicating thereby that DMABAB is capable of existing in the solid form in equilibrium with a liquid of the same composition.

3.1b DMABAB PNA system: In this system, we select IMC (DMABAB) as one parent component and the second component is PNA molecule and as such this system also shows the formation of a 1:1 IMC having congruent melting point and two eutectics $E_{1}$ and $E_{2}$ containing 0.25 and 0.60 mole fractions of DMABAB, respectively. There is hydrogen bonding and in the present case it is more convenient to say IMC [22] instead of addition compound. The melting points of $\mathrm{E}_{1}, \mathrm{E}_{2}$ and the IMC are 127,144 and $149^{\circ} \mathrm{C}$, respectively (figure 2). It is evident from the figure that the melting point of PNA decreases with the addition of the second component DMABAB and it attains the minimum value at the first eutectic point, just like the AA-DMAB system but in the present case $E_{1}$ composition is 1:1 of PNA and IMC (DMABAB-PNA) while in the above mentioned (AA-DMAB) case the ratio of $\mathrm{E}_{1}$ composition is 5:1 of AA and $D M A B A B$, respectively. The eutectic composition may depend upon size of parent molecules, IMC molecules as well as interstitial space available in all these molecules, and in the case of crystalline compound it is also dependent on the crystal system and space group. Some authors also believe that the eutectic point is a transition state of IMC in the case of hydrogen bonding.

\subsection{Spectroscopic studies on AA, DMAB, PNA, DMABAB and their IMCs}

AA: The peaks observed at 3325, 3240, 1677 and $1662 \mathrm{~cm}^{-1}$ in the spectrum of AA is indicative of $\mathrm{N}-\mathrm{H}, \mathrm{O}-\mathrm{H},>\mathrm{C}=\mathrm{O}$ stretching frequency of amine $\left(\mathrm{NH}_{2}\right)$, hydroxyl and carbonyl of carboxylic groups, respectively. In ${ }^{1} \mathrm{H}$ NMR $(300 \mathrm{MHz}$, $\left.\mathrm{CDCl}_{3}, \mathrm{ppm}\right)$ spectrum of AA the peaks appear at $\delta 6.67(4 \mathrm{H}$, d), $7.32(2 \mathrm{H}, \mathrm{t})$ and $7.94(1 \mathrm{H}, \mathrm{d})$.

DMAB: The peaks observed at 2795, 2713 and $1662 \mathrm{~cm}^{-1}$ in the spectrum of DMAB is due to $>\mathrm{C}=\mathrm{O}$ stretching frequency of aldehyde group. In ${ }^{1} \mathrm{H}$ NMR $\left(300 \mathrm{MHz}, \mathrm{CDCl}_{3}\right.$, 


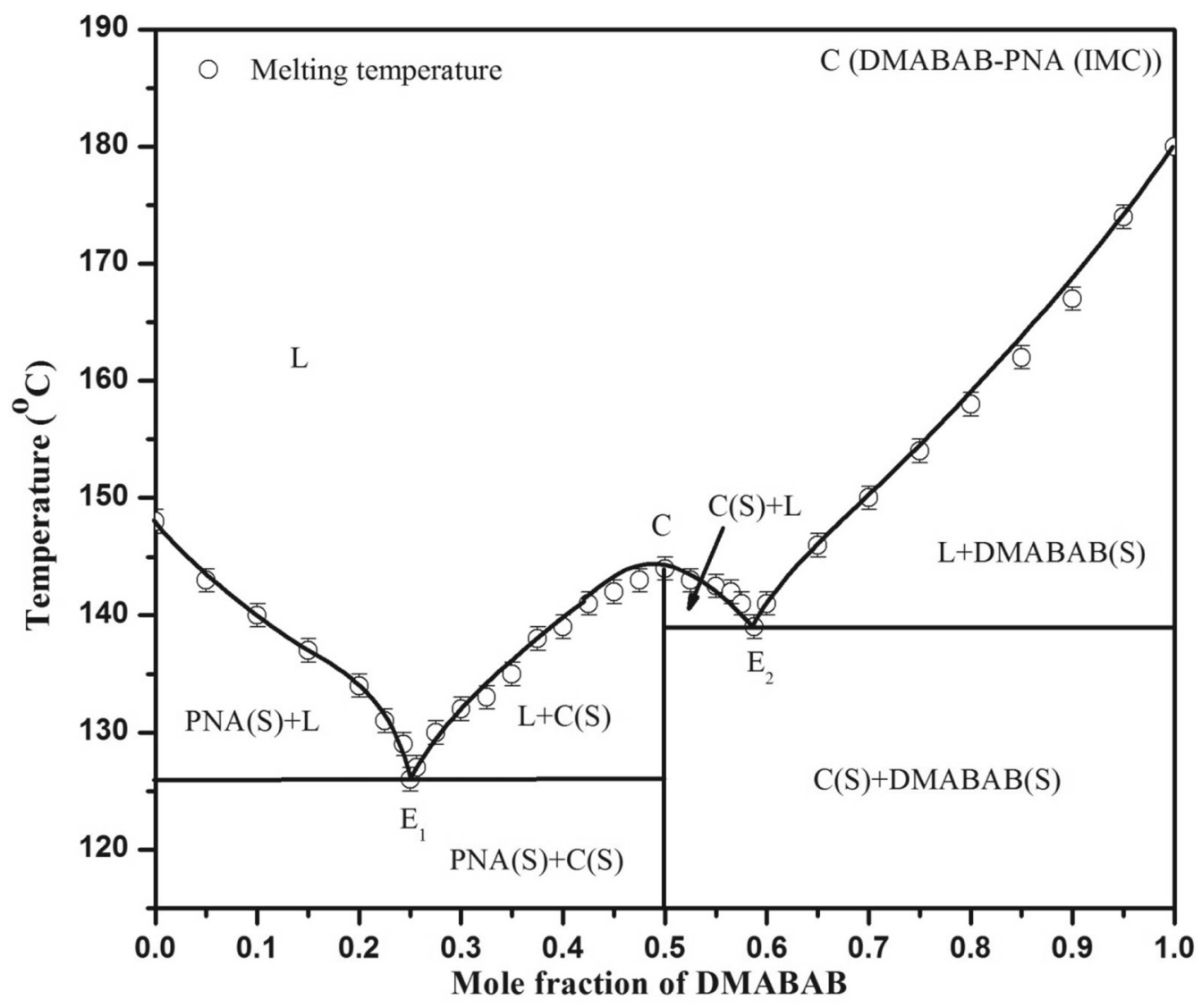

Figure 2. Phase diagram of DMABAB and PNA system.

ppm) spectrum of DMAB peaks appear at $\delta 9.87(1 \mathrm{H}, \mathrm{s})$, $\delta 7.63(2 \mathrm{H}, \mathrm{d}), \delta 6.78(2 \mathrm{H}, \mathrm{d})$ and $\delta 2.85(2 \mathrm{H}, \mathrm{d})$.

PNA: The peaks observed at 3432,3343 and $1681 \mathrm{~cm}^{-1}$ in spectrum of PNA is indicative of amine $\left(\mathrm{NH}_{2}\right),>\mathrm{C}=\mathrm{O}$ stretching frequency and carbonyl groups, respectively. In ${ }^{1} \mathrm{H}$ NMR $\left(300 \mathrm{MHz}, \mathrm{CDCl}_{3}, \mathrm{ppm}\right)$ spectrum of PNA the peaks appear at $\delta 7.97(2 \mathrm{H}, \mathrm{d}), \delta 6.97(2 \mathrm{H}, \mathrm{d})$ and $\delta 3.41$ (2H, s).

DMABAB: The peaks observed at 3434, 2922, 1677 and $1587 \mathrm{~cm}^{-1}$ in its spectrum is indicative of $\mathrm{O}-\mathrm{H}, \mathrm{N}-\mathrm{H},>\mathrm{C}=\mathrm{O}$ stretching frequency of hydroxyl, imine $(-\mathrm{C}=\mathrm{N}-)$ and carboxyl groups, respectively. In the ${ }^{1} \mathrm{H}$ NMR $\left(300 \mathrm{MHz}, \mathrm{CDCl}_{3}\right.$, ppm) spectrum of DMABAB peaks appear at $\delta 3.11(6 \mathrm{H}, \mathrm{s})$, $\delta 8.52(1 \mathrm{H}, \mathrm{s}), \delta 8.33(1 \mathrm{H}, \mathrm{d}), \delta 7.77(1 \mathrm{H}, \mathrm{t}), \delta 7.55(1 \mathrm{H}$, t), $\delta 7.44(1 \mathrm{H}, \mathrm{d}), \delta 7.33(2 \mathrm{H}, \mathrm{d}), \delta 6.77(2 \mathrm{H}, \mathrm{d})$ and $\delta 9.67$ (1H, s).

DMABAB-PNA (IMC): The shifts observed in $\mathrm{O}-\mathrm{H}$ and $>\mathrm{C}=\mathrm{O}$ stretching frequency of carbonyl and amine groups $\left(3183,1633\right.$ and $\left.1588 \mathrm{~cm}^{-1}\right)$ in the spectrum is due to hydrogen bonding and other peaks centred at 3481 and 3362 $\mathrm{cm}^{-1}$ are ascribed to the hydrogen bonded amine group of the PNA molecules. The ${ }^{1} \mathrm{H}$ NMR $\left(300 \mathrm{MHz}, \mathrm{CDCl}_{3}, \mathrm{ppm}\right)$ spectrum of IMC shows peaks at $\delta 9.73(1 \mathrm{H}, \mathrm{s}), \delta 3.08(6 \mathrm{H}$, s), $\delta 3.11(2 \mathrm{H}, \mathrm{s}), \delta 6.70(2 \mathrm{H}, \mathrm{d}), \delta 7.40(2 \mathrm{H}, \mathrm{d}), 8.33(1 \mathrm{H}, \mathrm{d})$, $\delta 8.11(2 \mathrm{H}, \mathrm{d}), 8.52(1 \mathrm{H}, \mathrm{s}), \delta 7.50(1 \mathrm{H}, \mathrm{d}), \delta 7.77(1 \mathrm{H}, \mathrm{t}), \delta$ $7.36(1 \mathrm{H}, \mathrm{t})$ and $\delta 6.66(2 \mathrm{H}, \mathrm{d})$.

\subsection{Enthalpy of fusion}

The idea about the structure of eutectic melt and the nature of interaction between the two components forming the eutectics and the addition compounds could be obtained from the knowledge of their enthalpy of fusion data. The DSC plots are shown in figures 3 and 4 for AA-DMAB and DMABABPNA systems, respectively. In the case of AA-DMAB system, $\mathrm{AA}$ has one more peak at $107^{\circ} \mathrm{C}$ in addition to their melting points which is due to the intra-molecular hydrogen bonding and the eutectic $\left(\mathrm{E}_{2}\right)$ also shows an additional peak at $101^{\circ} \mathrm{C}$ which is also due to the intra-molecular hydrogen bonding of AA. The DMABAB shows an additional peak at $70^{\circ} \mathrm{C}$ which may be due to the intra-molecular hydrogen bonding. The experimental values of enthalpy of fusion and the values that are computed using the mixture law [23] in the case of binary materials are included in table 1 . The values of enthalpy of mixing, which is the difference between the experimental and the calculated values of heat of fusion, is negative in the case of the AA-DMAB system, suggesting thereby a clustering of molecules for both binary eutectic melts [24] and in the 


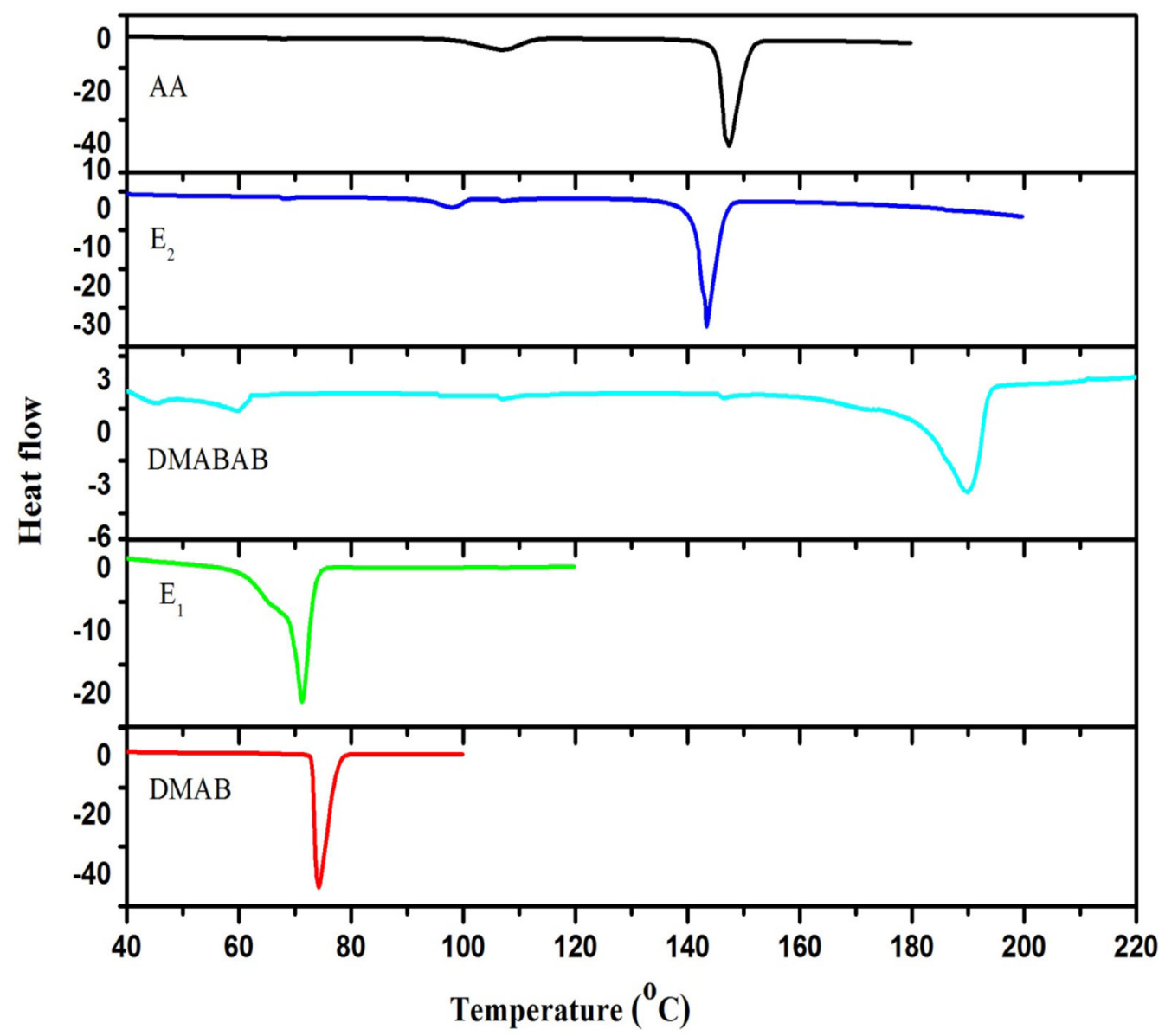

Figure 3. DSC plots of AA, DMAB, their eutectics and IMC (DMABAB).

case of the DMABAB-PNA system the value of enthalpy of mixing is positive for $E_{1}$ and negative for $E_{2}$, i.e., there is the formation of a quasi-eutectic structure in $\mathrm{E}_{1}$ melt [25] and clustering of molecules in $\mathrm{E}_{2}$ melt. The entropy of fusion $\left(\Delta_{\text {fus }} S\right.$ ) of the pure components, the eutectic and the addition compound as well as IMC can be calculated using the equation:

$$
\Delta_{\text {fus }} S=\frac{\Delta_{\text {fus }} H}{T}
$$

where $T$ is the melting temperature of the compound. The values of the entropy of fusion (table 1) being positive suggest that there is increase in randomness of the system during melting as expected. The enthalpy of fusion value also influences the critical radius and interfacial energy. When a melt is cooled below its equilibrium melting temperature, the liquid phase does not solidify spontaneously because, under equilibrium conditions, it contains a cluster of molecules. As long as the clusters are all below the critical size [26], they cannot grow to form crystals and, therefore, no solid would result. The interfacial energy $(\sigma)$ is related to the critical size $\left(r^{*}\right)$ of the nucleus according to the following equation:

$$
r^{*}=\frac{2 \sigma T_{\text {fus }}}{\Delta_{\text {fus }} H \cdot \Delta T}
$$

where $T_{\text {fus }}, \Delta_{\text {fus }} H$ and $\Delta T$ are melting temperature of eutectic, heat of fusion and degree of undercooling, respectively. The interfacial energy is given by the expression:

$$
\sigma=\frac{C \cdot \Delta_{\text {fus }} H}{\left(N_{\mathrm{A}}\right)^{1 / 3}\left(V_{\mathrm{m}}\right)^{2 / 3}}
$$

where $N_{\mathrm{A}}$ is the Avogadro number, $V_{\mathrm{m}}$ is the molar volume and parameter $C$ lies between 0.30 and 0.35 . The interfacial energies of pure components and eutectics were calculated by making use of enthalpy of fusion data and are reported in table 1. It is evident from the table that the value of interfacial energy is the maximum in the case of $\mathrm{AA}$ and it is the minimum in the IMC in the DMAB-AA system. On the other hand, in the case of the DMABAB-PNA system the value of 




Figure 4. DSC plots of DMABAB, PNA, their eutectics and IMC.

interfacial energy is the maximum in the case of DMABAB and it is minimum in the case of the IMC. It is well known that the interfacial energy is a measure of instability of formation of critical nucleus. Evidently, the role of interfacial energy is more important in the case of AA and DMABAB than those of IMCs in destabilization of the formation of critical nucleus.

\subsection{Excess thermodynamic functions}

A measure of deviation from ideal behaviour can be best expressed in terms of excess thermodynamic functions, namely, excess free energy $\left(g^{\mathrm{E}}\right)$, excess enthalpy $\left(h^{\mathrm{E}}\right)$ and excess entropy $\left(s^{\mathrm{E}}\right)$ which give a more quantitative idea about the nature of molecular interactions. The excess thermodynamic function $\left(Y^{\mathrm{E}}\right)$ is defined as the difference between the thermodynamic functions of mixing for a real system and the corresponding values for an ideal system at the same temperature and pressure. Thus,

$$
Y^{\mathrm{E}}=\Delta Y_{\text {mix }}(\text { real })-\Delta Y_{\text {mix }}(\text { ideal })
$$

where $Y$ is any of the excess thermodynamic function. The excess thermodynamic functions can be calculated using the equations reported earlier $[27,28]$ and the values are given in table 2 .

In the case of AA-DMAB system, positive values of excess free energy for both eutectic $\left(E_{1}\right.$ and $\left.E_{2}\right)$ indicate that the interaction between the like molecules (DMABDMAB, DMABAB-DMABAB and AA-AA) are stronger than the interaction between the unlike molecules (DMABDMABAB and DMABAB-AA) [27]. In the case of the DMABAB-PNA system both eutectic points have positive values of excess free energy i.e., at both eutectic point interactions between like molecules are stronger than unlike molecules (at $\mathrm{E}_{1}$ interaction between PNA-PNA and IMCIMC is stronger than PNA-IMC and at $\mathrm{E}_{2}$ interaction between DMABAB-DMABAB and IMC-IMC is stronger than DMABAB-IMC).

\section{$3.5 X R D$ studies}

Powder XRD patterns of parent compounds, their eutectics and addition compounds are recorded for AA-DMAB and DMABAB-PNA systems and the data are depicted in figures 5 and 6 , respectively. 


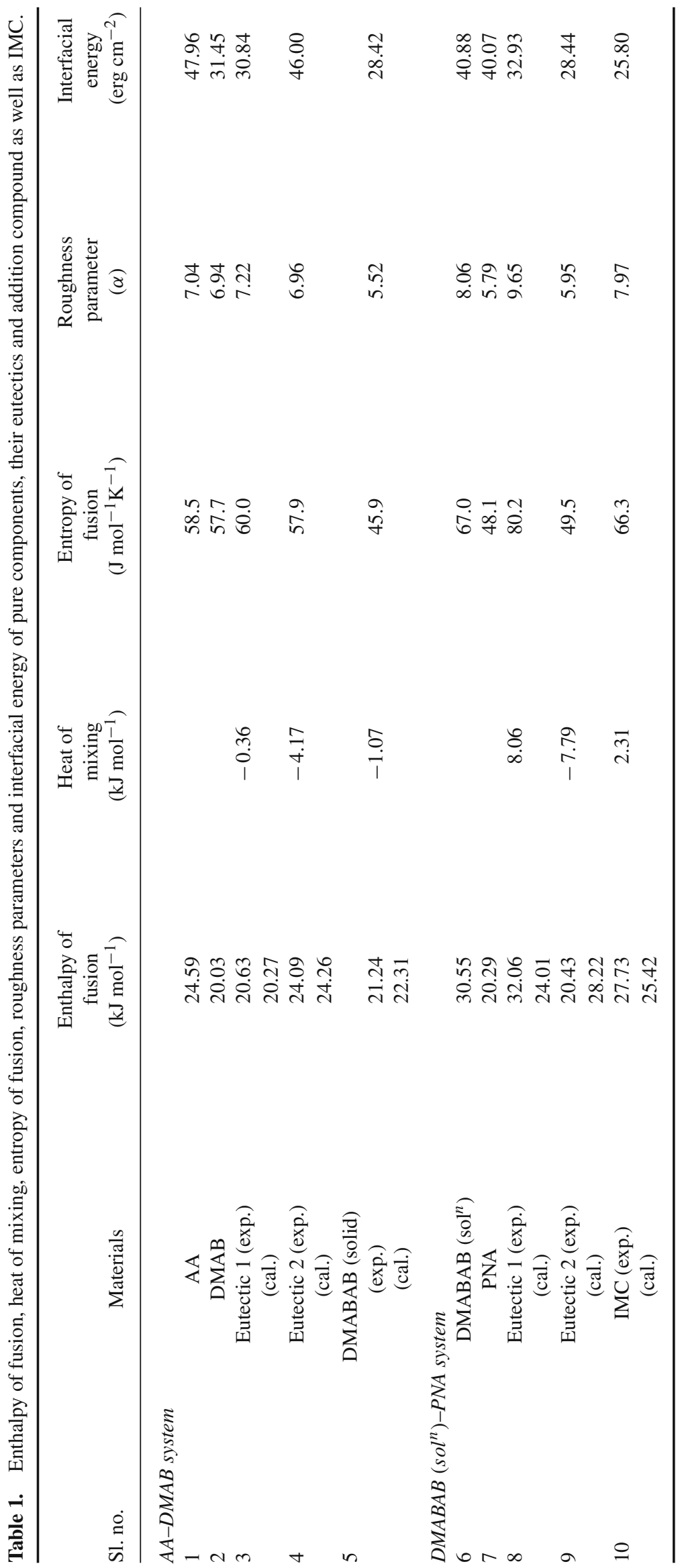


Table 2. Excess thermodynamic functions of eutectics of all three systems.

\begin{tabular}{|c|c|c|c|c|}
\hline Sl. no. & Systems & $g^{\mathrm{E}}\left(\mathrm{kJ} \mathrm{mol}^{-1}\right)$ & $h^{\mathrm{E}}\left(\mathrm{kJ} \mathrm{mol}^{-1}\right)$ & $s^{\mathrm{E}}\left(\mathrm{kJ} \mathrm{mol}^{-1} \mathrm{~K}^{-1}\right)$ \\
\hline \multicolumn{5}{|c|}{$A A-D M A B$ system } \\
\hline 1 & Eutectic 1 & 0.2013 & 8.4020 & 0.0238 \\
\hline 2 & Eutectic 2 & 0.4624 & -1.8704 & 0.0056 \\
\hline \multicolumn{5}{|c|}{$D M A B A B-P N A$ system } \\
\hline 3 & Eutectic 1 & 1.1793 & 4.9219 & 0.0094 \\
\hline 4 & Eutectic 2 & 0.8145 & 8.9341 & 0.0197 \\
\hline
\end{tabular}

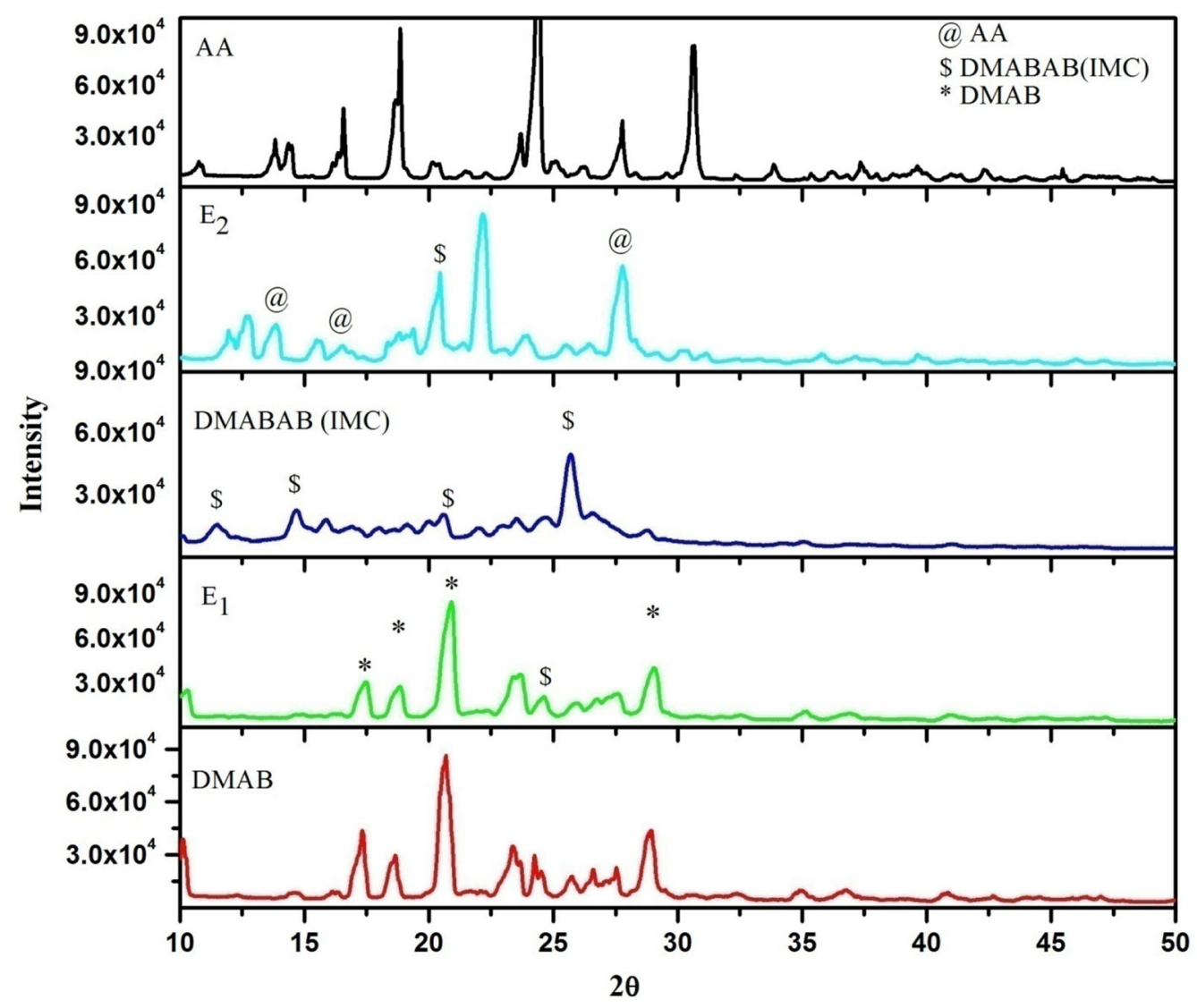

Figure 5. Powder XRD pattern of AA, DMAB, their eutectics and DMABAB.

In the case of the AA-DMAB system, it is evident from figure 5 that the XRD pattern of IMC (DMABAB) shows some new peaks which could not be assigned for either of parent components. In addition, a change in the intensity of some of the parent peaks was also observed. These observations confirm the formation of a new compound as DMABAB [21]. While the powder XRD pattern of the $\mathrm{E}_{1}$ shows almost all the peaks of AA compound and some peaks of DMABAB the $\mathrm{E}_{2}$ powder XRD pattern shows the peaks of the DMABAB and DMAB which confirm that at the eutectic point $E_{1}$, weak interactions exist between $D M A B$ and DMABAB and at eutectic $\mathrm{E}_{2}$ weak interactions exist between DMABAB and AA. For eutectic $\mathrm{E}_{1}$ the peaks of AA could not be assigned and similarly for eutectic $\mathrm{E}_{2}$ the peaks of DMAB could not be assigned and the peaks of DMABAB were present in both eutectics. From this observation it can be inferred that DMABAB behaves as a parent component for both eutectics. 




Figure 6. Powder XRD pattern of DMABAB, PNA, their eutectics and IMC.

In the case of the DMABAB-PNA system, it is evident from figure 6 that the XRD pattern of IMC shows a completely different set of peaks which could not be assigned for either of parent components and this confirms the formation of a new IMC [21]. The powder XRD pattern of $\mathrm{E}_{1}$ shows almost all the peaks of the PNA compound and IMC with different peak intensities, because the ratio of PNA and IMC at $E_{1}$ is $1: 1$ whereas at the $E_{2}$, powder XRD peak shows almost the same pattern as IMC, because the ratio of IMC and DMABAB at $E_{2}$ is $4: 1$ and there is no signature of PNA. Similar to the AA-DMAB system, both eutectics of this system also give only IMC X-ray peaks and corresponding parent compound peaks from which it can be inferred that the IMC behaves as a parent component for both eutectics.

\subsection{Optical characterization}

3.6a Absorption spectra: AA-DMAB system: The absorption spectrum of AA shows three bands at 216, 249 and
$335 \mathrm{~nm}$ ascribed to the $\sigma \rightarrow \pi^{*}, \pi \rightarrow \pi^{*}$ and $\mathrm{n} \rightarrow \pi^{*}$ transitions, respectively, and DMAB also gives three bands at 204, 242 and $341 \mathrm{~nm}$ ascribed to the $\sigma \rightarrow \pi^{*}, \pi \rightarrow \pi^{*}$ and $\mathrm{n} \rightarrow \pi^{*}$ transitions, respectively, figure 7a. The absorption spectrum of the IMC (DMABAB) shows three bands same as AA but with different intensities. The $\lambda_{\max }$ absorption shows hypochromic and hyperchromic shifts with respect to DMAB and $\mathrm{AA}$, respectively.

DMABAB-PNA system: PNA shows $\lambda_{\max }$ at $370 \mathrm{~nm}$ due to the $\mathrm{n} \rightarrow \pi^{*}$ transition and another band at $229 \mathrm{~nm}$ due to the $\pi \rightarrow \pi^{*}$ transition. DMABAB shows absorption maximum at $339 \mathrm{~nm}$ due to the $\mathrm{n} \rightarrow \pi^{*}$ transition and another band at $250 \mathrm{~nm}$ due to the $\pi \rightarrow \pi^{*}$ transition as shown in figure 8a. Absorption spectra of DMABAB-PNA IMC do not show any significant change at $\pi \rightarrow \pi^{*}$ transition band at $249 \mathrm{~nm}$. The $\lambda_{\max }$ at $370 \mathrm{~nm}$ has a broad range of absorption which shows red shift $(9 \mathrm{~nm})$ with respect to PNA with a hump at $380 \mathrm{~nm}$. This red shift in IMC is due to the intermolecular hydrogen bonding between both parents [29]. 

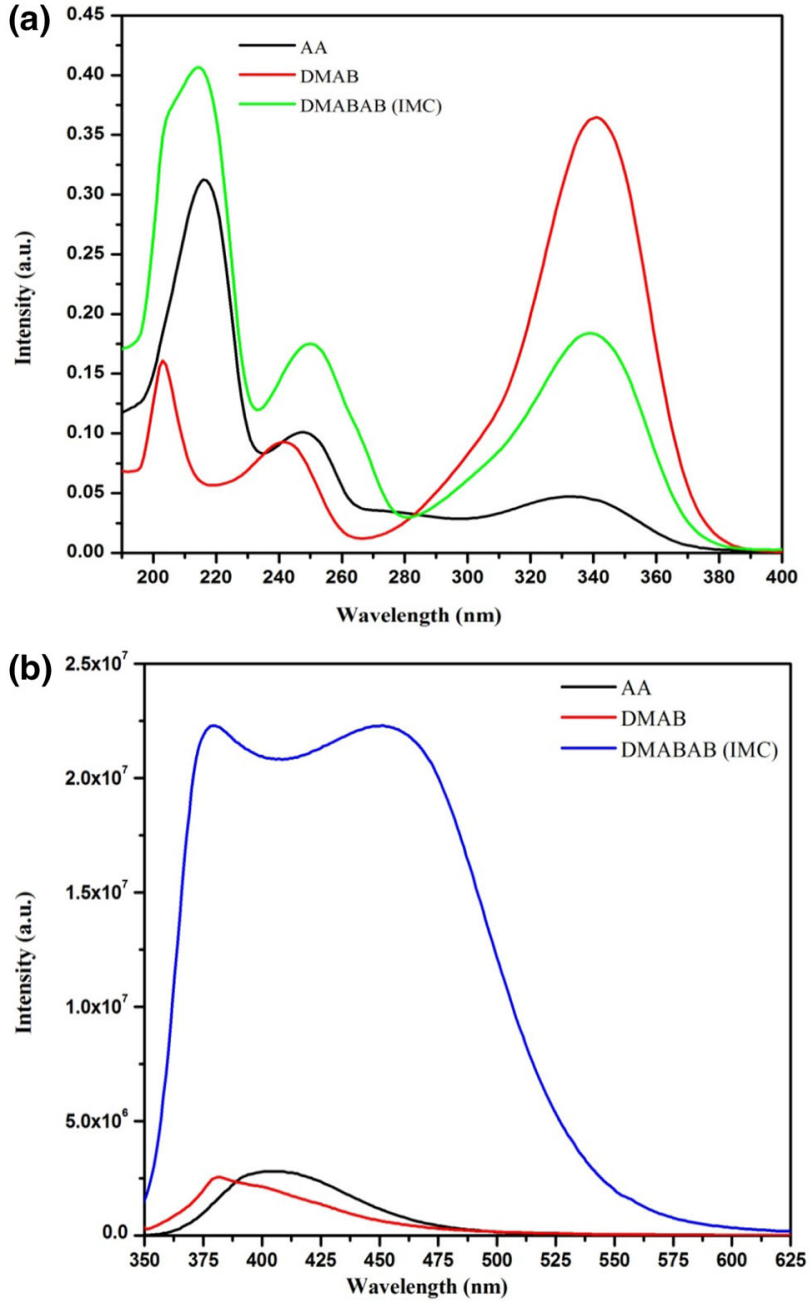

Figure 7. (a) Absorption spectra and (b) emission spectra of AA, DMAB and their DMABAB.

3.6b Emission spectra: DMAB-AA system: DMAB and AA show very low emission with $\lambda_{\max } 380 \mathrm{~nm}$ and $\lambda_{\max }$ $405 \mathrm{~nm}$ upon their $\lambda_{\max }$ excitation, respectively. DMABAB IMC shows strong dual emission with two $\lambda_{\max }$ : one at $380 \mathrm{~nm}$ and the second at $450 \mathrm{~nm}$ (Stokes' shift 39 and $112 \mathrm{~nm}$ ) upon excitation at $339 \mathrm{~nm}$, figure $7 \mathrm{~b}$. The total quantum efficiency of DMABAB was found to be 0.49 .

DMABAB-PNA system: PNA shows very low emission with $\lambda_{\max } 418 \mathrm{~nm}$ upon excitation at $371 \mathrm{~nm}$. DMABAB gives strong dual emission with two $\lambda_{\max }$ one at $380 \mathrm{~nm}$ and the other at $450 \mathrm{~nm}$ (Stokes' shift 39 and $112 \mathrm{~nm}$ ) upon excitation at $339 \mathrm{~nm}$ as shown in figure 8b. DMABAB-PNA IMC also shows strong dual emission with two $\lambda_{\max }$ : one at $390 \mathrm{~nm}$ and second at $435 \mathrm{~nm}$ (Stokes' shift 42 and $87 \mathrm{~nm}$ ). First emission peak shows a red-shift of $12 \mathrm{~nm}$ and the second emission peak shows a blue-shift of $16 \mathrm{~nm}$. Total quantum efficiency $(0.31)$ of IMC is less than that of DMABAB quantum efficiency (0.49).
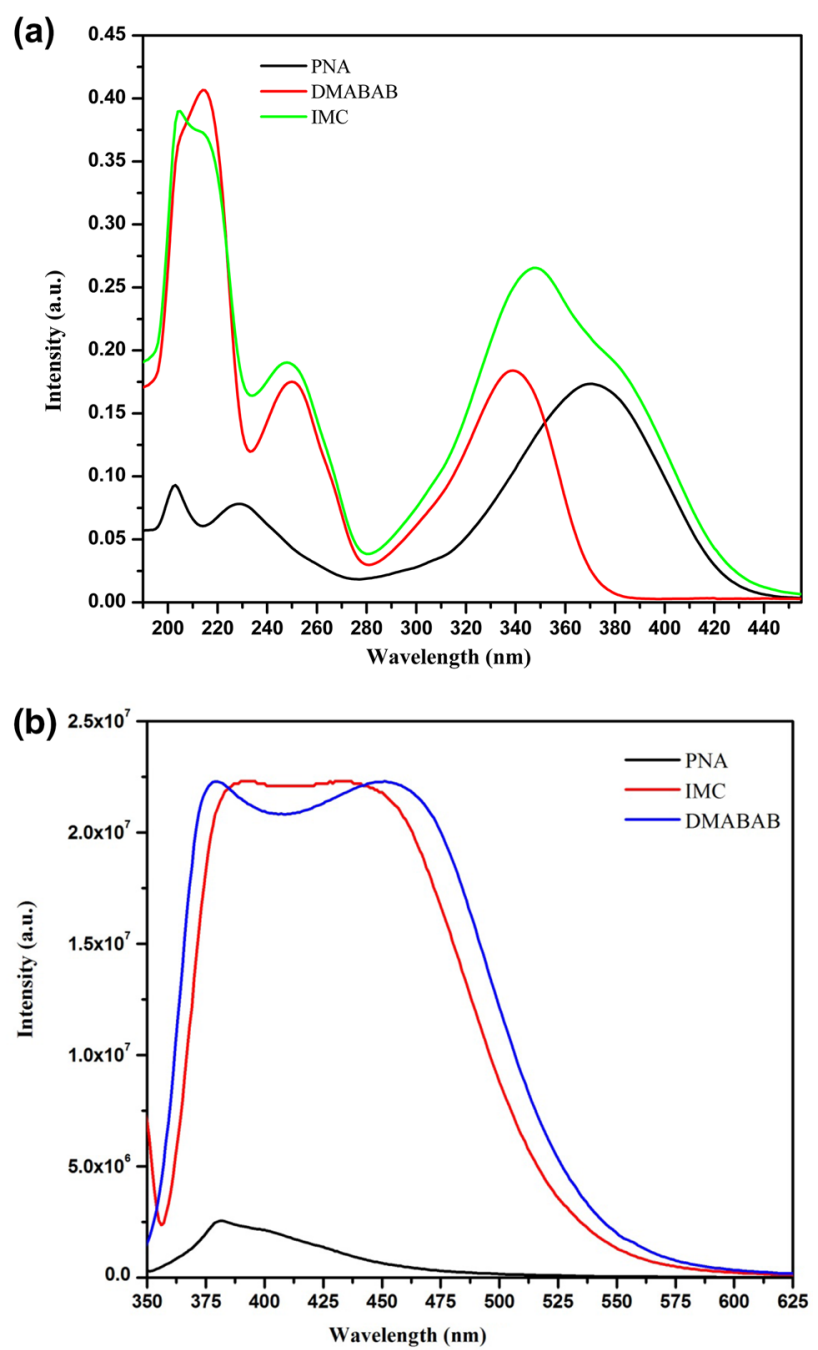

Figure 8. (a) Absorption spectra and (b) emission spectra of DMABAB, PNA and their IMC.

\section{Conclusions}

The phase diagram of two systems, namely, DMAB-AA and DMABAB-PNA shows the formation of 1:1 IMC with congruent melting point and two eutectics one on either side of the IMC. The spectroscopic studies suggest the formation of hydrogen bonding between both parents in DMABABPNA and AA-DMAB systems. The heat of mixing is negative in the case of the AA-DMAB system, suggesting thereby a clustering of molecules for both binary eutectic melt and in the case of the DMABAB-PNA system the enthalpy value of mixing is positive for $E_{1}$ and negative for $E_{2}$ i.e., there is the formation of quasi-eutectic structure in $E_{1}$ melt and clustering of molecules in $\mathrm{E}_{2}$ melt. The powder XRD patterns confirm the formation of IMC that behaves as a pure component for both eutectics, which supports the phase diagram data. The DMABAB IMC shows strong dual emission with two $\lambda_{\max }$ : one at $380 \mathrm{~nm}$ and second at $450 \mathrm{~nm}$ with a 
total quantum efficiency of 0.49. DMABAB-PNA IMC also shows strong dual emission with two $\lambda_{\max }$ : one at $390 \mathrm{~nm}$ and second at $435 \mathrm{~nm}$ with a total quantum efficiency of 0.31 .

\section{Acknowledgement}

One of the authors (Dr Manjeet Singh) would like to thank UGC for providing a research fellowship.

\section{References}

[1] Rudrakshi G B, Pathak J P and Ojha S N 2002 Indian Foundry J. 4817

[2] Ellott R 1983 Eutectic solidification processing (London: Butterworths)

[3] Majumdar B and Chattopdhyay K 2000 Metall. Mater. Trans 31A 1

[4] Facchetti A, Yoon M H and Marks T J 2005 Adv. Mater. 17 1705

[5] Forest S R 2004 Nature 428911

[6] Loo Y L and McCulloch I 2008 Mater. Res. Bull. 33353

[7] Horiuchi S and Tokura Y 2008 Nat. Mater. 7357

[8] Horiuchi S, Kumari R and Tokura Y 2007 Angew. Chem. Int. Ed. 463497

[9] Desiraju G R 1995 Angew. Chem. Int. Ed. Engl. 342311

[10] Rai R N, Reddi R S B and Rai U S 2013 Prog. Cryst. Growth Character. Mater. $\mathbf{5 9} 73$
[11] Muthuraman R, Masse R, Nicoud J F and Desiraju G R 2001 Chem. Mater. 131473

[12] Costa M C, Rolemberg M P, Boros L A D, Kralhenbu1hl M A, de Oliveira M G and Meirelles A J A 2007 J. Chem. Eng. Data $\mathbf{5 2} 30$

[13] Rice J W and Suuberg E M 2010 J. Chem. Thermodyn. 421356

[14] Dwivedi Y, Kant S, Rai R N and Rai S B 2010 Appl. Phys. B 101639

[15] Rai R N, Mudunuri S R, Reddi R S B, Ganeshmurthi V S A K and Gupta S K 2011 J. Cryst. Growth 32172

[16] Dean J A 1985 Lange's handbook of chemistry (New York: McGraw-Hill)

[17] Singh M, Pandey P, Rai R N and Rai U S 2013 J. Therm. Anal. Calorim. 113977

[18] Dwivedi Y, Kant S, Rai S B and Rai R N 2011 J. Fluoresc. 21 1255

[19] Abbott A P, Capper G, Davies D L, Rasheed R K and Tambyrajah V 2003 Chem. Commun. 170

[20] Abbott A P, Boothby D, Capper G, Davies D L and Rasheed R K 2004 J. Am. Chem. Soc. 1269142

[21] Rai R N and Varma K B R 2000 Mater. Lett. 44284

[22] Stahly G P 2009 Cryst. Growth Des. 94212

[23] Rai R N 2004 J. Mater. Res. 191348

[24] Singh M, Rai R N and Rai U S 2011 Am. J. Anal. Chem. 2953

[25] Rai U S and Rai R N 1998 J. Cryst. Growth 191234

[26] Christian J W 1965 The theory of phase transformation in metals and alloys (Oxford: Pergamon Press) p. 992

[27] Singh N, Singh N B, Rai U S and Singh O P 1985 Thermochim. Acta 95291

[28] Rai R N and Rai U S 2000 Thermochim. Acta 36323

[29] Kalsi P S 2005 Spectroscopy of organic compounds (India: New Age Publication) 6th edition $\mathrm{p} 1$ 